\title{
Nurses' perceptions related to impaired nurses and knowledge of substance use disorder within the nursing profession
}

\author{
Rhonda K. Pecoraro, Susan B. Prude, Dari K. Calamia, Eileen L. Creel \\ Nursing, Southeastern Louisiana University, Hammond, Louisiana, United States
}

Received: January 28, 2021

DOI: $10.5430 /$ jnep.v11n8p32
Accepted: April 5, 2021

Online Published: April 12, 2021

URL: https://doi.org/10.5430/jnep.v11n8p32

\begin{abstract}
Objective: Substance Use Disorder continues to be a problem within the nursing profession. Studies have been conducted to examine various aspects of Substance Use Disorder. Although programs have been implemented to help rather than punish nurses, knowledge barriers that affect reporting still exist. The purpose of this study was to examine nurses' perceptions of impaired nurses, perceptions of reporting an impaired nurse, and perceptions of knowledge regarding Substance Use Disorder within the nursing profession.

Methods: A mixed-method descriptive study was conducted using the Perception of Nursing Impairment Inventory tool, as well as three open-ended questions. Lazarus and Folkman's Transactional Model of stress and coping was used to guide the study and nurses from one state's nurses' association in the southeastern region of the United States participated.

Results: Based on quantitative findings, most disagreed with the statement there is little that can be done to help impaired nurses and agreed that nurses have an ethical obligation to report if impairment is suspected. Conflicting views were identified for multiple statements on the Perception of Nursing Impairment Inventory. The qualitative findings revealed average or below average knowledge of SUD and identified barriers that may affect reporting. Further, a culture surrounding the ethical dilemma of reporting was evident.

Conclusions: Educational gaps exist between recognizing and reporting the problem of Substance Use Disorder. Although nurses acknowledge an obligation to report, many barriers to reporting were identified. Recommendations were made for additional qualitative research related to nursing education including conflicted feelings about doing what is "right."
\end{abstract}

Key Words: Substance use disorder, Substance misuse, Substance abuse, Addiction, Impaired nurse, Reporting

\section{INTRODUCTION}

Substance abuse (SA) is a term that has been used for many years to describe the use of illegal drugs, or inappropriate use of legal drugs or alcohol. Substance misuse is a newer term, equivalent in meaning to SA, but without the negative connotation. According to the National Institute on Drug Abuse (NIDA), the term SA is rarely used by profession- als any longer because the stigma or shame associated with it could discourage individuals from seeking help. ${ }^{[1]}$ Substance misuse can be related to a single drug or multiple drugs, including alcohol. When a person is under the influence of drugs or alcohol, they may be considered impaired. Impairment refers to the "inability or impending inability to provide safe, professional activities and duties due to a

\footnotetext{
*Correspondence: Rhonda K. Pecoraro; Email: rhonda.pecoraro@ selu.edu; Address: Nursing, Southeastern Louisiana University, Hammond, Louisiana, United States.
} 
behavioral, mental, or physical disorder related to alcohol or drugs." ${ }^{2]}$ Physical dependence and addiction are negative consequences often associated with substance misuse. Physical dependence refers to the body's reaction to the regular use of a legal or illegal substance that may result in withdrawal symptoms if the substance is abruptly stopped. Dependence can occur without misuse, as an individual may become dependent on a prescribed medication even if it is taken as directed. However, addiction is more commonly associated with using an illegal substance or repeated misuse of a legal substance. Addiction is a more serious condition defined as "a chronic, relapsing disorder characterized by compulsive drug seeking, continued use despite harmful consequences, and long-lasting changes in the brain." ${ }^{[1]}$ Although addiction is a term commonly used, it is not a specific diagnosis in the fifth edition of The Diagnostic and Statistical Manual of Medical Disorders (DSM-5). ${ }^{[1,3]}$ In 2013 the DSM was updated, the terms substance abuse and substance dependence were removed and replaced with the umbrella term substance use disorder (SUD).$^{[1]}$ For the sake of this document, most of the terms have been updated from SA to substance misuse and SUD. However, in some cases, it was more appropriate to keep the original wording used by the authors, as to not change the meaning associated with the research tool or study findings.

The results of the 2019 National Survey on Drug Use and Health shows an upward trend in the use of illicit drugs among Americans aged 12 or older over the past five years. In 2019, 20.8\% reported use of an illicit drug during the past year, an increase from $17.8 \%$ in 2015. The number of persons aged 12 or older classified with SUD was reported to be 20.4 million (7.4\%). This number has remained relatively constant when compared to results from previous surveys. ${ }^{[4]}$ Substance use and misuse contribute to significant health burdens in the United States, costing upward of $\$ 600$ billion dollars annually. ${ }^{[5]}$ There are a variety of explanations and predisposing factors that may cause some individuals to be more susceptible to SUD than others. ${ }^{[6]}$ Examples include family, peer and social influences, genetics, childhood sexual abuse, low self-esteem, and attempts to self-medicate symptoms associated with mental illness. SUD does not discriminate; individuals from various backgrounds and professions are affected. ${ }^{[7-9]}$

The research findings concerning the incidence of SUD among nurses have varied over the past 20 years, ranging from $6 \%-20 \%$, with approximately $10 \%$ being the most common consensus, which is equivalent to that of the general population. ${ }^{[9-13]}$ Although the most common consensus is approximately $10 \%$, some researchers indicate higher numbers associated with nurses and addiction. According to a

Published by Sciedu Press study by Kunyk, most of the nurses that coded high risk for impaired practices were working, without treatment, and without recognition by employer or regulator. ${ }^{[9]}$ Thomas and Siela estimated that one in ten, or 10\%-15\% of all nurses may be impaired or in recovery from alcohol or drug addiction. ${ }^{[14]}$ Difficulty in determining an accurate number for nurses experiencing SUD may stem from under-reporting related to lack of recognition, and fear of reprisal from employers or licensing boards. ${ }^{[8,9]}$ Although nurses may not be at higher risk for SUD than individuals from other professions or of the general population, conditions exist within the healthcare environment that may cause nurses to be more vulnerable to SUD. Nursing is a profession that is very stressful at times and can lead to poor decision-making and poor coping skills. Stress, extended work shifts, high-acuity settings, rotating shifts, required overtime, and working short-staffed are work conditions for many nurses and could contribute to SUD. ${ }^{[6]}$ Other factors that put nurses at higher risk for SUD include easy access to drugs while at work ${ }^{[7,15]}$ denial of a problem, and attempts to self-medicate due to knowledge of medications. ${ }^{[7,8,15]}$

The statistical information associated with SUD, primarily related to nursing, may be inaccurate due to underreporting. Underreporting can be attributed to many factors such as failure to recognize the problem within oneself or others, denial of a problem, fear of the consequences of reporting or being reported, and feelings of shame. ${ }^{[11,16]}$ Additionally, some believe nurses have an educational background on addiction and therefore will be able to avoid suffering from a SUD themselves. Many nurses suffering from addiction experience stigma from others and often stigmatize themselves, which can lead to guilt, shame, and embarrassment. ${ }^{[7,16]}$ Nursing is a profession deeply rooted in moral and ethical practices. The Nightingale pledge indicates acknowledgment that SUD within the nursing profession is unacceptable behavior: "I solemnly pledge myself before God ... I will abstain from whatever is deleterious and mischievous, and will not take or knowingly administer any harmful drug. I will do all in my power to maintain and elevate the standard of my profession ..." "[17]

Nurses strive to adhere to the commitment of the pledge while providing care for patients, self, colleagues, and the reputation of the profession. In addition to the Nightingale Pledge, the American Nurses Association (ANA) provides a Code of Ethics for Nurses with Interpretive Statements that nurses are expected to uphold. ${ }^{[18]}$ This code speaks specifically to the nurse's ethical obligation to protect the patient/public from unsafe nursing practice in Provision 3.5 "Protection of Patient Health and Safety by Acting on Questionable Behavior." ${ }^{[18]}$ One way that nurses support each 
other, their patients, and the profession is by recognizing and responding to a nurse colleague demonstrating signs of impairment.

\subsection{Significance}

The dangers, costs, and consequences associated with SUD can be detrimental to anyone, but when the impaired individual is a nurse, the potential for disastrous results is amplified. Although the incidence of SUD among nurses is thought to be equivalent to that of the general population, the consequences associated with the disease may be greater for nurses as an impaired nurse presents the possibility of harm to patients. A nurse's ability to safely perform routine skills may be diminished while under the influence of certain medications or alcohol. Impaired practice as defined by the ANA may include "mental or physical illness, fatigue, substance abuse, or personal circumstances." ${ }^{[18]}$ A nurse working while impaired does not only affect the nurse involved, but can also affect patients' safety, facilities' costs, and the reputation of the nursing profession. ${ }^{[13,19]}$ Foli et al. describes a cascade effect that occurs when a nurse is caught misusing substances. ${ }^{[6]}$ The negative ramification of SUD affects the accused, peers, middle management, supervisors, as well as the entire unit.

Many programs have been implemented by various nursing organizations to assist, rather than punish, nurses suffering from SUD. The ANA acknowledged the severity of the problem in 1982 when a specific task force was developed to explain the problem of nursing and addiction, offer suggestions for program development, and to assist with recovery efforts. ${ }^{[20]}$ However, nurses are still reluctant to self-report the misuse of a substance due to fear of the consequences should disclosure occur. ${ }^{[9]}$ Failure to self-report may be due to a variety of reasons including lack of knowledge concerning available resources, denial of a problem, and fear of negative consequences, such as loss of family, loss of employment, required participation in a rehabilitation program, shame, and the stigma associated with being labeled a drug addict. $^{[7,9,11]}$ Nurses may fail to report suspicions of an impaired colleague due to lack of knowledge concerning SUD and the reporting process, uncertainties about suspicions, and fear of negative consequences such as loss of friendships, and the stigma of being labeled a whistleblower. According to a study by Kunyk, 91\% of nurses who self-reported having SUD were working without their employer or peers knowing while Cares et al. found that $37 \%$ of those who self-reported as abusing at least one substance felt there were signs of their misuse which peers could have recognized. ${ }^{[7,9]}$ The majority $(98 \%)$ of nurses surveyed by Kunyk, did know they had an obligation to report an impaired nurse. ${ }^{[9]}$
Lack of knowledge of SUD as a problem within the nursing profession, along with a failure to understand signs of SUD and identify those who may be suffering from SUD could contribute to this ongoing problem. ${ }^{[9]}$ It is imperative that nurses are knowledgeable of the prevalence, predisposing factors, signs, and symptoms of SUD among peers. They should feel confident to recognize and report an impaired nurse and understand the ethical and legal obligation to report known or suspected impairment. Any behavior with the potential to put oneself, colleagues, healthcare facilities, patients, or the reputation of the nursing profession at risk should be reported. Lack of knowledge or negative perceptions toward impaired nurses have the potential to delay reporting, which in turn could result in delayed recognition of the problem, treatment, and potential for recovery. ${ }^{[7,13,15,18,21,22]}$

\subsection{Purpose of the study}

The purpose of this research study was to provide information about nurses' perceptions of impaired nurses, nurses' perceptions of reporting an impaired nurse, and nurses' perceptions of knowledge regarding SUD within the nursing profession. The data obtained from this study may provide valuable information related to impaired nurses and SUD within the nursing profession; thus, identifying educational needs for current and future nurses.

\subsection{Research questions}

1) What are nurses' perceptions of impaired nurses?

2) What are nurses' perceptions of reporting an impaired nurse?

3) What are nurses' perceptions of knowledge regarding Substance Use Disorder within the nursing profession?

\section{METHODS}

\subsection{Study design}

There are limitations to quantitative and qualitative research when a moral or ethical topic such as SUD is the focus of the study. Based on the sensitive nature of the research topic, an anonymous mixed-method research design was chosen. A quantitative descriptive survey along with three open-ended qualitative questions were used. The quantitative portion allowed for the structured collection of information using an established tool. However, the need to place a numeric value to the quantitative data can be viewed as a limitation, as a large portion of nursing research is related to complex human experiences that are best understood through the collection of narrative data. Although qualitative research allows for in-depth subjective findings, this approach can also have limitations depending on the research topic. Some participants may be reluctant to talk openly about moral or ethical issues in face-to-face interviews. Based on this knowledge and the 
sensitive nature of the research topic, the three open-ended questions were added to the end of the questionnaire that was sent via Survey Monkey, allowing participants to freely express their feelings without fear of being judged by the surveyor. The use of a mixed-method approach allows for the strengths of both designs to be utilized while limiting the weaknesses, thus providing a better understanding of the problem being studied. ${ }^{[23]}$

Lazarus and Folkman's transactional model of stress and coping was used as the theoretical framework to guide the study. Based on the transactional model, a person's reaction to an external event is not determined by the event itself, but rather the individual's appraisal of the event and judgment concerning perceived internal and external demands as compared to the availability of resources. ${ }^{[24]}$ Individuals respond to a situation with a primary appraisal. If there is a perceived threat, then a secondary appraisal occurs. The individual's perception of their ability to cope will determine the outcome of the situation. Therefore, the outcome of a situation is determined by the appraisal of the event rather than the actual event. This is based on one's perception of resources versus demand. The transactional model can be used in situations related to a nurse resorting to alcohol or drug use, as well as a situation related to a nurse's decision to report or not report an impaired colleague. For example, suspicion or knowledge of an impaired nurse is considered the event. A primary appraisal determines if the event presents a threat or potential for harm. If the answer is yes, then a secondary appraisal occurs. During the secondary appraisal, the nurse determines knowledge of the reporting process and availability of resources. If a nurse knows what to do, understands ethical obligations and responsibilities, knows who to report to, and knows the process for reporting, the nurse is more likely to report. If a nurse does not know what to do or does not know the steps to take, or fears the consequences of reporting, it will likely lead to a decision to not report.

\subsection{Setting}

Nurses from one state's nurses' association in the southeastern region of the United States were invited to participate in the online study via email.

\subsection{Sample}

A convenience sample was utilized based on the following inclusion criteria: participants must be 18 years old or older, a current or past registered nurse, and a current member of the state's nurses' association. There were no exclusions for participation based on gender, educational background, employment status, years of nursing experience, or job position. The MaCorr Research Sample Size Calculator was used to determine the desired sample size, using a 5\% interval and a $95 \%$ confidence index. ${ }^{[25]}$ The total number of possible participants consisted of the 1,279 members of the selected state's nurses' association. The sample was drawn from the participants who voluntarily completed the survey. Based on the MaCorr Research Sample Size Calculator the desired sample size was 296 participants. The actual sample size consisted of 281 participants, yielding a $22 \%$ response rate.

\subsection{Ethical consideration}

Prior to recruitment and data collection, ethical approval was obtained from the ethics review board of the state's nurses' association. Members of the association were contacted via email by a representative of the association inviting them to participate in the research study. A cover letter was included which explained the purpose of the study. The email provided a link to the survey with instructions on how to access the link. Participants were informed that accessing the SurveyMonkey ${ }^{\circledR}$ link indicated consent to participate in the study. All responses remained anonymous and were stored on a passcode-protected flash drive and secured in a locked safe when not in use. Only members of the research team had access to the data.

\subsection{Instrumentation}

An online survey was used to gather data for the study. A tool created by the researcher was used to collect demographic data. The Perceptions of Nursing Impairment Inventory (PNII) tool was used to collect data related to nurses' perceptions of impaired nurses. Three open-ended questions at the end of the survey were used to collect information related to nurses' perceptions of knowledge regarding SUD within the nursing profession. The survey was available through SurveyMonkey ${ }^{\circledR}$ and took approximately 10-20 minutes to complete.

The PNII tool was developed in 1987 at the University of Kentucky for a project titled Nurses Assisting Nurses. ${ }^{[26]}$ The tool consists of 32 statements related to nursing impairment and uses a four-point Likert scale for nurses to indicate: (1) strongly agree, (2) agree, (3) disagree, or (4) strongly disagree. A convenience sample of 72 nurses was used to pilot test the PNII instrument. A Cronbach alpha reliability coefficient of .82 was obtained. ${ }^{[26]}$ Validity for the PNII tool was established through use in greater than 60 studies within the subsequent 5 years of the tool's development and initial use. ${ }^{[27]}$ The PNII tool continues to be used in current research studies related to SUD. ${ }^{[9,28]}$

The first six questions of the survey included the following demographic information: age, gender, educational background, employment status, years of nursing experience, 
and job position. The demographic information collected provided information about the characteristics of the sample. Statements 7 through 38 were collected using the PNII tool and provided quantitative information about nurses' perceptions of impaired nurses and their perceptions related to reporting an impaired nurse. Questions 39 through 41, were open ended and were used to obtain a richer understanding of the nurses' perceptions of knowledge and reporting of an impaired nurse.

\section{RESUlTS}

The majority of the 281 participants were female $(n=258$, 92\%). The most frequent response for Age was 50-59 $(\mathrm{n}=$ $81,29 \%)$. Many of the participants had master's degree educational level $(\mathrm{n}=125,45 \%)$, followed by bachelor's degree $(\mathrm{n}=70,25 \%)$, then doctorate $(\mathrm{n}=57,20 \%)$. The majority of participants reported employment status as working full-time in nursing ( $\mathrm{n}=229,82 \%)$, with nurse educator as the most common response to the question of position held $(n=100$, $39 \%)$.

\subsection{Research Question One}

\section{What are nurses' perceptions of impaired nurses?}

Twenty-six general statements related to nurses' perceptions of impaired nurses were selected from the 32 item PNII tool. Descriptive analysis for the selected statements was provided through the use of SSP version v1.15.10.16 software.

The responses to $81 \%$ of the statements regarding impaired nurses, 21 of the 26 , indicated the participants had very similar perceptions, either agreeing with or disagreeing with the statements. Statements number 31 and 32 yielded nearly unanimous responses. Nearly all (99\%) of the participants disagreed or strongly disagreed with the following statement, "There is little that can be done to help nurses who are impaired," while $98 \%$ of the participants agreed or strongly agreed that the State Board of Nursing's responsibility should include offering the impaired nurse referral to sources of assistance. Overall, most of the responses from the participants were similar, with only five statements revealing conflicting opinions. Approximately half (52\%) agreed a nurse can continue to work while enrolled in a treatment program, while $48 \%$ disagreed. A little less than half (43\%) believed they have a right to know if a coworker is receiving treatment for SUD, while 57\% did not agree with this information being shared. Similarly, $41 \%$ viewed impairment as a widespread problem among nurses, while 58\% disagreed and did not see it as a problem in nursing. The ability to recognize and offer assistance to an impaired coworker also revealed differences of opinions, with only $52 \%$ of the participants agreeing they could recognize an impaired coworker, and $48 \%$ indi- cating a lack of ability to recognize. When made aware of a coworker's impairment, $40 \%$ agreed they could offer assistance to help, while $60 \%$ did not feel they could help. Table 1 contains the 26 statements from the PNII tool along with the responses that were collected and used to assess nurses' perceptions of impaired nurses.

\subsection{Research Question Two}

What are nurses' perceptions of reporting an impaired nurse?

Six statements, more specific to nurses' perception of reporting an impaired nurse, were selected from the 32 item PNII tool. Descriptive analysis for the selected statements was provided through the use of SSP version v1.15.10.16 software.

The majority of the participants agreed or strongly agreed that impaired nurses should not be approached directly (73\%), but instead that nurses have an obligation to notify the supervisor if an impairment is suspected of a colleague (99\%). The majority also agreed or strongly agreed that when a nursing supervisor has concrete evidence that a nurse is impaired; the supervisor has a responsibility to suspend that individual immediately pending investigation of the charges and report the information to the State Board of Nursing. Two of the statements indicated a difference of opinions, with nearly an even split between participants that agreed and disagreed. Fifty-one percent agreed or strongly agreed, while $49 \%$ disagreed or strongly disagreed with the following statement: When a nurse has reason to believe that a co-worker is impaired, he/she has a responsibility to help that person obtain assistance. The other statement in which participants had a split opinion was: When impairment occurs, it is more likely to be reported in nursing than in other health-related fields, 54\% agreed or strongly agreed while $46 \%$ disagreed or strongly disagreed. Additional information concerning frequencies and percentages for nurses' perceptions of reporting an impaired nurse is presented in Table 2.

\subsection{Research Question Three}

\section{Qualitative data analysis}

Three open-ended questions were used to elicit participant knowledge about impaired nurses and the impact of that knowledge on reporting practices which included,

1) What is your perception of knowledge of substance abuse within the nursing profession?

2) How would your knowledge of substance abuse within the nursing profession affect your decision to report or not report an impaired nurse?

3) What barriers to nurses' knowledge of substance abuse 
within the nursing profession can you identify?

Although participants did respond with answers about their knowledge along a continuum ranging from "limited" to "expert," most frequently the participants took the opportunity allowed by these open-ended questions, to tell their stories, thoughts, and perceptions surrounding working with an impaired nurse, as well as the process and moral angst of reporting an impaired nurse. These responses supported the quantitative data findings from the PNII survey where nurses were split in their perceptions and will be presented in Table 3.

Table 1. Frequencies and percentages for perceptions related to impaired nurse

\begin{tabular}{|c|c|c|c|c|}
\hline \multirow{2}{*}{ Variables - PNII Statements } & \multicolumn{2}{|l|}{$\mathrm{N}(\%)$} & \multicolumn{2}{|l|}{ N (\%) } \\
\hline & $S A$ & $\boldsymbol{A}$ & $\bar{D}$ & SD \\
\hline Q7 Impaired nurses - suffer from an illness. & $89(33 \%)$ & $144(54 \%)$ & $28(10 \%)$ & $6(2 \%)$ \\
\hline Q8 Impaired nurse is often related to stressful situations of job. & $10(4 \%)$ & $81(30 \%)$ & $149(56 \%)$ & $27(10 \%)$ \\
\hline Q9 Most impaired nurses can continue to work while receiving treatment. & $16(6 \%)$ & $123(46 \%)$ & $104(39 \%)$ & $24(9 \%)$ \\
\hline $\begin{array}{l}\text { Q10 Nursing supervisor has a responsibility to help an impaired nurse obtain } \\
\text { assistance. }\end{array}$ & $143(54 \%)$ & $107(40 \%)$ & $12(5 \%)$ & $4(2 \%)$ \\
\hline Q11 If an impaired nurse is receiving treatment, co-workers should be aware. & $37(14 \%)$ & $77(29 \%)$ & $120(46 \%)$ & $29(11 \%)$ \\
\hline $\begin{array}{l}\text { Q12 In most cases, public safety should require impaired nurses’ licenses be } \\
\text { revoked. }\end{array}$ & $11(4 \%)$ & $52(20 \%)$ & $160(61 \%)$ & $41(16 \%)$ \\
\hline Q13 Becoming impaired is something that could happen to almost any nurse. & $66(25 \%)$ & $126(47 \%)$ & $63(24 \%)$ & $12(4 \%)$ \\
\hline Q14 If an impaired nurse is receiving treatment, the supervisor should be aware. & $170(64 \%)$ & $86(32 \%)$ & $6(2 \%)$ & $4(2 \%)$ \\
\hline $\begin{array}{l}\text { Q15 The help needed by an impaired nurse requires insight that only other nurses are } \\
\text { likely to provide. }\end{array}$ & $11(4 \%)$ & $31(12 \%)$ & $181(68 \%)$ & $43(16 \%)$ \\
\hline $\begin{array}{l}\text { Q16 In most cases, problems of impaired nurses stem from difficulties prior to } \\
\text { nursing. }\end{array}$ & $51(19 \%)$ & $146(55 \%)$ & $63(24 \%)$ & $5(2 \%)$ \\
\hline $\begin{array}{l}\text { Q18 In most cases, public safety can be assured by probationary period of licensure } \\
\text { of the impaired nurse. }\end{array}$ & $52(20 \%)$ & $165(63 \%)$ & 39 (15\%) & $8(3 \%)$ \\
\hline $\begin{array}{l}\text { Q19 Even after treatment, it is unusual for an impaired nurse to be productive and } \\
\text { trustworthy. }\end{array}$ & $3(1 \%)$ & $6(2 \%)$ & $150(56 \%)$ & 107 (40\%) \\
\hline Q20 Impairment is a widespread problem among nurses. & $25(9 \%)$ & $86(32 \%)$ & 135 (51\%) & $19(7 \%)$ \\
\hline $\begin{array}{l}\text { Q22 Most impaired nurses could be helped in a support group with other impaired } \\
\text { nurses. }\end{array}$ & $51(19 \%)$ & $166(62 \%)$ & $46(17 \%)$ & $4(1 \%)$ \\
\hline $\begin{array}{l}\text { Q23 SBN must provide the nurse information on legal \& due process rights in } \\
\text { disciplinary procedures. }\end{array}$ & $182(69 \%)$ & $73(28 \%)$ & $7(3 \%)$ & $2(1 \%)$ \\
\hline $\begin{array}{l}\text { Q24 I could probably recognize an impaired nurse in the work setting by his/her } \\
\text { appearance or behavior. }\end{array}$ & $8(3 \%)$ & $129(49 \%)$ & $104(40 \%)$ & $22(8 \%)$ \\
\hline $\begin{array}{l}\text { Q26 Major health care agencies should be required to provide employee assistance } \\
\text { programs. }\end{array}$ & $104(39 \%)$ & $126(47 \%)$ & $31(12 \%)$ & $5(2 \%)$ \\
\hline $\begin{array}{l}\text { Q27 Problems of impaired nurses are similar to other individuals with substance } \\
\text { abuse \& emotional issues. }\end{array}$ & $62(23 \%)$ & 145 (55\%) & $50(19 \%)$ & $7(3 \%)$ \\
\hline $\begin{array}{l}\text { Q28 For public protection the SBN should continue to publish the names of all } \\
\text { nurses found to be impaired. }\end{array}$ & $55(21 \%)$ & $117(44 \%)$ & $62(23 \%)$ & $31(12 \%)$ \\
\hline $\begin{array}{l}\text { Q29 Impairment occurs less frequently in nursing than in other health care related } \\
\text { fields. }\end{array}$ & $3(1 \%)$ & $17(6 \%)$ & $181(69 \%)$ & $63(24 \%)$ \\
\hline Q30 Impairment is generally a result of a weakness in the nurse's personality. & $5(2 \%)$ & $19(7 \%)$ & $120(45 \%)$ & $121(46 \%)$ \\
\hline Q31 There is little that can be done to help nurses who are impaired. & $2(1 \%)$ & $1(0 \%)$ & $101(38 \%)$ & $161(61 \%)$ \\
\hline $\begin{array}{l}\text { Q32 SBN's responsibility should include offering the impaired nurse referral to } \\
\text { sources of assistance. }\end{array}$ & $161(61 \%)$ & $99(37 \%)$ & $2(1 \%)$ & $4(2 \%)$ \\
\hline $\begin{array}{l}\text { Q34 Impaired nurses should not be allowed to work until successfully complete } \\
\text { treatment program. }\end{array}$ & $104(39 \%)$ & $100(38 \%)$ & $51(19 \%)$ & $9(3 \%)$ \\
\hline $\begin{array}{l}\text { Q36 When made aware of co-workers impairment, fellow nurses are often able to } \\
\text { offer assistance. }\end{array}$ & $6(2 \%)$ & $99(37 \%)$ & $141(53 \%)$ & $19(7 \%)$ \\
\hline $\begin{array}{l}\text { Q37 SBN should provide resources to support research on prevention \& treatment } \\
\text { for impaired nurses. }\end{array}$ & $115(43 \%)$ & $123(46 \%)$ & $22(8 \%)$ & $5(2 \%)$ \\
\hline
\end{tabular}

Note. $\mathrm{SA}=$ strongly agree, $\mathrm{A}=$ agree, $\mathrm{D}$ = disagree, $\mathrm{SD}$ = strongly disagree, $\mathrm{SBN}=$ State Board of Nursing. Due to rounding error, percentages may not add up to 100 . Statement wording was consolidated for use in the table. 
Table 2. Frequencies and percentages for nurses' perceptions of reporting an impaired nurse

\begin{tabular}{|c|c|c|c|c|}
\hline \multirow{2}{*}{ Variables - PNII Statements } & \multicolumn{2}{|l|}{ N (\%) } & \multicolumn{2}{|l|}{ N (\%) } \\
\hline & $S A$ & $A$ & $D$ & $S D$ \\
\hline $\begin{array}{l}\text { Q17 Supervisors have a responsibility to suspend an impaired nurse } \\
\text { pending an investigation. }\end{array}$ & 113 (43\%) & $127(48 \%)$ & $22(8 \%)$ & $3(1 \%)$ \\
\hline $\begin{array}{l}\text { Q21 Nurses have an obligation to notify a supervisor if he/she suspects a } \\
\text { coworker is impaired. }\end{array}$ & 167 (63\%) & 95 (36\%) & $1(0 \%)$ & $2(1 \%)$ \\
\hline $\begin{array}{l}\text { Q25 Supervisors have a responsibility to dismiss an impaired nurse and } \\
\text { report to the SBN. }\end{array}$ & $64(24 \%)$ & 97 (37\%) & $80(30 \%)$ & $23(9 \%)$ \\
\hline $\begin{array}{l}\text { Q33 When a nurse has reason to believe a co-worker is impaired, he/she } \\
\text { has a responsibility to help that nurse obtain assistance. }\end{array}$ & $37(14 \%)$ & 99 (38\%) & 109 (41\%) & $19(7 \%)$ \\
\hline $\begin{array}{l}\text { Q35 Impairment, when it occurs is more likely to be reported in nursing } \\
\text { than in other health related fields. }\end{array}$ & $28(11 \%)$ & 115 (44\%) & 102 (39\%) & $19(7 \%)$ \\
\hline $\begin{array}{l}\text { Q } 38 \text { When suspecting impairment is a co-worker, a nurse's first response } \\
\text { should be to confront the nurse. }\end{array}$ & $11(4 \%)$ & $59(22 \%)$ & $146(55 \%)$ & $49(18 \%)$ \\
\hline
\end{tabular}

Trustworthiness is always of concern for the qualitative piece of a mixed-methods study. ${ }^{[29]}$ To ensure trustworthiness, participants replied in writing and anonymously to three openended questions delivered via SurveyMonkey ${ }^{\circledR}$. Because the participants wrote in their own words, transcription was not needed so verbatim language was easily ensured. Data were analyzed using thematic analysis by three researchers with qualitative experience and then triangulated for consistency of final themes. Responses to each question were read for keywords and phrases, with a grouping of commonalities.

Table 3. Participant responses

\begin{tabular}{|c|c|}
\hline \multicolumn{2}{|l|}{ In Their Own Words } \\
\hline Duty to Report & Failure to Report \\
\hline “ethical obligation’ & "Afraid to report due to supervisor not believing me." \\
\hline "protect the patient" & “grossly underreported” \\
\hline "my responsibility” & "there is a lot of denial" \\
\hline "duty to protect the public" & "often people to choose to ignore the signs" \\
\hline "protect patients"; "public safety” & “time”; “too busy”; “nurses are so busy” \\
\hline "patients come first" & "rationalize the behavior they see instead of being \\
\hline "safeguarding patient safety” & responsible and reporting” \\
\hline "save the nurse" & "relationships with co-workers" \\
\hline "best interest of the organization, the public, and the ill employee" & "apathetic view of the situation” \\
\hline “prevent dire consequences” & “fear retribution” \\
\hline "helping a co-worker" & “denial and refusal to get involved” \\
\hline "safety of the profession” & It is a "dark secret”; "taboo"; "not talked about” \\
\hline 'morally and professional obligated to report" & "no one wants to get anyone in trouble" \\
\hline “duty to report it" & "nurses are caregivers, but look the other way" \\
\hline "not reporting is dangerous and puts everyone in a liable situation" & \\
\hline
\end{tabular}

Dichotomous and contradictory themes were identified from the participant responses to the three open-ended questions. Because of the contradictory nature of the themes a moral dilemma and possible moral distress seems evident. One theme indicated the participants' strong understanding and knowledge of a professional Duty to Report, while on the 
other hand, the second theme addressed a Failure to Report.

\subsubsection{Theme One: Duty to report}

Participants overwhelmingly stated that they had a "duty," "moral obligation," "ethical obligation," and even a "legal obligation" to report an impaired nurse. They cited these beliefs as being predicated on their knowledge of the ANA Code of Ethics, teaching from their nursing education programs, and Standards of Practice from their Boards of Nursing. Participants indicated that they would report as it was their duty, but also indicated they would report an impaired nurse to protect patients from unsafe or possible harmful nursing practice. One nurse who echoed many others said, "Public safety should be protected above all," while another wrote, "The patient's safety is priority." In addition to the patients' safety, many nurses shared that reporting was also a way for them to ensure the impaired nurse received helpful treatment for their addiction saying, "I believe they need to be reported to get help" and "... it is often the first step to treatment."

\subsubsection{Theme Two: Failure to report}

As strong as the participants' conviction about the ethical, legal, and moral obligation to report, the second theme, failure to report, was equally powerful, as revealed through their shared narratives.

Nurses reported that SUD was "common," "widespread," "more widespread than most would imagine," and "a largescale problem in nursing." These were just a few of many comments about the scale of the problem. Some believe this to be related primarily to "stress on nurses," "burnout," and "easier access to medications." Despite the belief that impaired nurses are a "serious problem" an overwhelming number of participants reported that they would need "concrete" evidence and "evidence... beyond any doubt" before they would report any suspicion of a nurse working while impaired. Nurses also indicated they believed reporting was not only "under reported" but "grossly underreported" and "covered up." Participants cited a wide variety of reasons for the failure to report from widespread "denial," SUD being a "taboo" topic and something "not talked about" to the stigma associated with having a substance use disorder. Additionally, many nurses shared that they were "too busy" as the reporting process was time-consuming and that they "didn't want to get involved," along with fear of reprisal, fear of lost friendship, or fear of being seen as a "bad person" for reporting.

Though the open-ended questions poised were intended to elicit a rich response about nurses' knowledge and possible education needs, what was discovered was the foundations of intense moral angst for nurses surrounding SUD related to

Published by Sciedu Press the nursing profession. A dichotomy exists between nurses' responses related to their full understanding and belief in their ethical obligation to report, as opposed to their feelings of reporting as being "taboo" which elicited feelings of fear and denial of the problem thus creating the space for this moral dilemma. A knowledge or education deficit was found in responses with over half self-identifying as having average or below average knowledge. Many participants indicated they could use additional training on the reporting process or behaviors to observe to help identify a nurse with SUD who may be working while impaired. However, additional education did not come through in the responses as being beneficial in that many self-identified as having "expert" knowledge while still failing to report.

A larger issue seems to be what many participants talked about as a "culture" of the workplace ("environments that we work in"), of the nursing profession, and even society at large which stigmatizes having a SUD and reporting a person who may be impaired by a SUD. Additionally, many participants shared thoughts about how a nurse with a SUD is often "judged," "shamed," "has lost his/her moral compass," and it is like "wearing the 'A' upon their chest." Beliefs that a SUD diagnosis is a "personal choice" remained commonly threaded throughout their comments such as, "it is a bad habit," and "most think it is a weakness." Nurses feel "little is being done to diminish the work-related factors that contribute to substance abuse." See Table 3 for participant responses.

\section{Discussion}

Limited sample size and a low response rate were identified as limitations to this study, however valuable information was obtained. Based on the quantitative findings, the respondents did not see SUD as a widespread problem in nursing and had positive attitudes toward impaired nurses, with $99 \%$ disagreeing with the following statement: "There is little that can be done to help nurses who are impaired." The use of the PNII tool in other studies yielded similar positive findings and allowed for direct comparisons of statements. For example, SUD is not a weakness but rather an illness that is treatable and can happen to almost any nurse..$^{[9,26,28]}$ This message comes through in the quantitative findings as well, but some of the qualitative responses revealed contradictory opinions such as, "Most think it is a weakness and usually not a disease" and "once a nurse has a substance addiction he or she is marked." A study conducted by Ross et al. found that nurses with SUD were viewed differently, and less deserving of empathy compared to nurses with other health issues. ${ }^{[16]}$ The research findings concerning SUD as a widespread problem in nursing have varied over the past 20 
years, ranging from $5 \%-20 \%$, with approximately $10 \%$ being the most common consensus, which is equivalent to that of the general population..$^{[9,11,15]}$ An accurate prevalence rate is difficult to identify due to underreporting. According to a study by Cares, $48 \%$ of participants reported drug or alcohol use while at work, and $40 \%$ felt their competency levels were affected. ${ }^{[7]}$

Nearly all participants acknowledged an obligation to notify the manager when impairment is suspected (99\%), but alarmingly, only $52 \%$ indicated an ability to recognize an impaired nurse based on appearance or behavior. These findings are almost identical to the results $(98 \% ; 53 \%)$ from a study reported by Kunyk in response to the same statements from the PNII tool. ${ }^{[9]}$ This could be another factor to support the belief that the actual number of nurses suffering from SUD is higher than what is currently reported. Recognizing a nurse colleague or identifying oneself as an impaired nurse, can be influenced by an individual's knowledge and perceptions of SUD. Recognizing an impaired nurse is an important first step, but what happens next - reporting suspicions of impairment related to SUD can be equally, if not more important.

Although $99 \%$ of the quantitative responses confirm agreement that nurses have an obligation to notify a manager if a colleague is suspected to be impaired, which indicated an understanding of the nurse's obligation to report but did not give a definitive answer as to whether the nurse would report. Many authors have provided numerous reasons why nurses do not report impairment or SUD including lack of knowledge, failure to recognize the problem within oneself or others, denial of a problem, fear of the consequences of reporting or being reported, and shame. ${ }^{[6,11]}$ According to a study by Cares more than two thirds of the respondents that admitted to working impaired, felt that their problem could have been recognized sooner. ${ }^{[7]}$ A study by Evan-Mitchell, as cited by Zickafoose revealed that while $61 \%$ of participants reported working with an impaired nurse, only $45 \%$ reported a colleague with a SUD. ${ }^{[19]}$ Two of the PNII statements designated to provide information about nurses' perceptions of reporting an impaired nurse revealed responses that indicated opposing views. One of the questions did not specifically identify reporting as the intervention, but instead asked for a response to the statement: "If a nurse has reason to believe a colleague is impaired, he/she has a responsibility to help that person obtain assistance." Fifty-one percent agreed with the statement, while $49 \%$ disagreed. To fully understand the respondents' view, an explanation of the meaning of assistance would need to be provided. Another area associated with reporting that the respondents did not agree on was reporting in nursing versus other health-related fields. Fifty-four per- cent agreed that reporting is more likely to occur in nursing than in other health-related fields. However, many studies indicate that healthcare professionals are more likely to underreport substance use due to fear of repercussions. ${ }^{[7-9,15]}$ Issues related to under-reporting of impairment in nursing were also identified through the qualitative findings from this study and will be discussed.

The qualitative component of the study was related to nurses' perceptions of knowledge of SUD within the profession and how it may affect one's decision to report an impaired nurse. Over half of the respondents reported adequate, average, or below-average knowledge of SUD. Most that identified themselves to be knowledgeable indicated knowledge through years of work experience, on-the-job experience, working as a manager or supervisor, or from working in a mental health setting. Some respondents also stated that although knowledgeable of SUD within the profession, there were times of disbelief associated with the news of an impaired colleague, which had not previously been detected. The barriers to reporting associated with lack of knowledge were very broad and included statements such as "not enough education provided on the topic in nursing curriculums" or in hospital orientation programs, "it is not talked about often enough," inability to recognize an impaired nurse, uncertainties about how to intervene or report. Very few respondents mentioned educational background, continuing education class, or facility orientation programs as a contributing factor to knowledge concerning SUD. A common statement among the respondents that identified as having adequate, average, or below-average knowledge, was a desire for more information or knowledge on the subject.

In addition to lack of education related to SUD many other barriers to reporting were noted such as fear, denial, shame, lack of concern, as well as nurses protecting nurses. These barriers to reporting were consistent with those found in other studies. ${ }^{[9,11]}$ Comments concerning fear were related to reporting or being reported. The fear associated with being reported included: fear of losing a job or license, fear of the stigma associated with being labeled an addict, and fear of the state board of nursing investigation process. Fears associated with reporting included: fear of falsely accusing someone, fear of retaliation, fear of hurting a friend, and fear of being considered "a rat" by other colleagues. Denial was associated with self-identification of a problem, "it could never happen to me" and denial concerning wrongdoing by a friend/colleague, "she is a good nurse." Many comments linked denial to a lack of concern, nurses not wanting to get involved, or because "nurses are always on the go...maybe too busy to realize a coworker is impaired." Shame was mainly linked to the impaired nurses' perception 
of self, ashamed of becoming addicted, and letting family, colleagues, and the profession down. This sense of shame is echoed by findings from Ross et al. that revealed nurses suffer from SUD in silence, maintaining their secret, to avoid the disgrace associated with exposure. ${ }^{[16]}$

The anonymous open-ended question format used in the qualitative portion of this study allowed participants to voice their opinions about impaired nurses and SUD without fear of judgment. Not all participants answered the questions in the context intended but instead used it as an open forum to share their thoughts, feelings, and past experiences. As a result, what the researchers obtained were the uncensored feelings about the contradictory ethical dilemma that many nurses face when it comes to reporting self or an impaired coworker. The responses brought to light the moral struggle between doing what is "right for the patient" and the nursing profession and doing what is "right" for a friend/colleague. One might question, is reporting suspected impairment the right thing to do if there will be negative consequences for the person reporting and the person being reported? Although many participants indicated that knowledge on the topic of SUD would affect their decision to report, most said they would report regardless of their knowledge on the topic because it is the right thing to do; a "moral/ethical obligation." However, this acknowledgment of an obligation to report was often followed by, if "concrete evidence" of impairment was observed. This statement brought the researchers to question, do nurses really understand their obligation? Are nurses obligated to report suspicious behaviors that could potentially cause harm to patients, coworkers, and the reputation of the nursing profession or should they only report suspicions of impairment if concrete evidence is available? Based on the findings from this study most nurses are aware of their obligation to report, but many justified reasons why one may be reluctant or slow to report.

\section{Conclusion}

The current study identified nurses' perception of impaired nurses and perceptions of reporting an impaired nurse, as well as areas of weakness related to knowledge of SUD within the nursing profession. Weaknesses included lack of ability to recognize an impaired nurse, lack of education related to SUD within the nursing profession, limited knowledge about how to assist an impaired nurse, and many barriers related to knowledge of SUD that could affect reporting, such as fear, shame, guilt, denial, loyalties, and friendships. Although much research has been conducted and programs for assistance have been implemented, SUD continues to be a problem within the nursing profession, and many nurses remain reluctant to report suspected impairment or SUD.

\section{Recommendations}

Based on the findings from this study additional research related to SUD within the nursing profession is recommended. This need is supported by the findings from Boulton and Nosek's study which revealed that fewer than half of the students surveyed indicated adequate education concerning SUD was provided in nursing school and did not feel that they could competently recognize an impaired nurse. ${ }^{[28]}$ According to the quantitative results of this study, $99 \%$ stated that an impaired nurse should be reported, however, only $52 \%$ acknowledged the ability to recognize an impaired nurse based on appearance or behavior. These findings alone suggest a need for additional education, while the results of the qualitative findings further confirm the need. A qualitative study would allow for greater exploration and understanding of the perceptions and themes identified in this study.

Nursing curricula should be reviewed to determine the extent to which SUD within the nursing profession is being covered and where it is taught in the program in relation to other courses. Health care employee orientation and continuing education programs should also be reviewed to determine how much information is provided on the topic and whether clear guidelines for reporting suspected or known impairment exists. Nurse educators have a responsibility to adequately prepare future nurses. Nurses should be aware of the prevalence of SUD within the profession, be able to identify signs and symptoms of impairment, know how to report impairment, and have knowledge of available resources for help if needed. The negative stigma and shame associated with SUD must be eliminated.

\section{Conflicts of InTEREST Disclosure}

The authors declare that they have no competing interests.

\section{REFERENCES}

[1] U.S. Department of Health and Human Services, National Institutes of Health, National Institute on Drug Abuse. The science of drug use and addiction: The basics; [internet]. Bethesda (MD): National Institutes of Health; [updated 2018 Jul; cited 2020 Dec]. Available from: https://www.drugabuse.gov/publications/media-g uide/science-drug-use-addiction-basics

[2] Toney-Butler TJ, Siela D. Recognizing alcohol and drug impairment in the workplace in Florida [Internet]. Bethesda (MD): National Center for Biotechnology Information. National Library of Medicine. 
c2020 [cited 2020 Dec]. Available from: https ://www.ncbi.nlm .nih.gov/books/NBK507774/2020

[3] American Psychiatric Association, Diagnostic and statistical manual of mental disorders. 5th ed. Washington DC: American Psychiatric Association; c2013.

[4] U.S. Department of Health and Human Services, Substance Abuse and Mental Health Services Administration. Key substance health indicators in the United States: Results from the 2019 national survey on drug use and health; [internet] Rockville, MD: Center for Behavioral Health Statistics and Quality, Substance Abuse and Mental Health Services Administration; 2020 Sep [cited 2020 Dec]. Available from: https://store.samhsa.gov/sites/default/files/produ ct_thumbnails/PEP20-07-01-001-thumbnail-1_0.JPG

[5] U.S. Department of Health and Human Services, National Institutes of Health, National Institute on Drug Abuse. Principles of drug addiction treatment: A research-based guide (Third Edition) [internet]. Bethesda (MD): National Institutes of Health; [updated 2018 Jan; cited 2021 Jan]. Available from: https://www.drugabuse.gov/publications/principle s-drug-addiction-treatment-research-based-guide-t hirdedition/frequently-asked-questions/how-can-fam ily-friends-make-difference-in-life-someone

[6] Foli KJ, Reddick B, Zhang L, et al. Substance use in registered nurses: "I heard about a nurse who...". J Am Psychiatr Nurses Assoc. 2020 Jan-Feb; 26(1): 65-76. PMid:31747853 https://doi .org/10.1 $177 / 1078390319886369$

[7] Cares A, Pace E, Denious, et al. Substance use and mental illness among nurses: Workplace warning signs and barriers to seeking assistance. Subst Abus. 2015 May; 36: 59-66. PMid:25010597 https://doi.org/10.1080/08897077.2014.933725

[8] Elalla EA, Awaad M, Elhabiby M, et al. Substance abuse among nursing staff: Prevalence and sociodemographic and clinical characteristics. Addict Disorders and Their Treat. 2020 Jun; 19(2): 99-107. https://doi.org/10.1097/ADT.0000000000000191

[9] Kunyk D. Substance use disorders among registered nurses: prevalence, risks, and perceptions in a disciplinary jurisdiction. $\mathrm{J}$ Nurs Manag. 2015 Jan; 23(1): 54-64. PMid:23952722 https ://doi.or g/10.1111/jonm. 12081

[10] Bozimowski G, Ghoh, Rouen P, et al. The prevalence and patterns of substance abuse among nurse anesthesia students. JAm Assoc Nurse Anesth. 2014 Aug; 82(4): 277-283.

[11] Burton KL. Emerging from the darkness and stepping into the light: Implementing an understanding of the experience of nurse addiction into nursing education. J Nurs Educ Pract. 2014 April; 4(4): 151-164. https://doi .org/10.5430/jnep.v4n4p151

[12] Monroe TB, Kenaga H, Dietrich M S, et al. The prevalence of employed nurses identified or enrolled in substance use monitoring programs. Nurs Res. 2013Jan-Feb; 62(1): 10-15. PMid:22960589 https://doi.org/10.1097/NNR.0b013e31826ba3ca

[13] National Council of State Boards of Nursing. Substance use disorder in nursing: A resource manual and guidelines for alternative and disciplinary monitoring programs [internet]. Chicago:National Council of State Boards of Nursing; c2011[cited 2020 Dec]. Available from: https://www.ncsbn.org/SUDN_11.pdf

[14] Thomas CM, Siela D. The impaired nurse: Would you know what to do if you suspected substance abuse? AM Nurs Today. 2011 Aug; 6(8): $1-6$.

[15] Mumba MN, Kraemer KR. Substance use disorders among nurses in medical-surgical, long-term care, and outpatient services. Medsurg Nursing. 2019 Mar-April; 28(2): 87-92.

[16] Ross CA, Jakubec SL, Berry NS, et al. "A two glass of wine shift": Dominant discourses and the social organization of nurses' substance use. Glob Qual Nur Res. 2018 Dec/Jan; 5: 1-12. PMid:30480040 https://doi .org/10.1177/2333393618810655

[17] Nightengale's Nursing [Internet]. Florence Nightengale's pledge. 2015. Available from: http://nightingalesnursing.net/fl orence-nightingale-pledge/

[18] American Nurses Association [Internet]. Code of ethics for nursing with interpretive statements. American Nurses Association. 2015. Available from: https://www.nursingworld.org/practic e-policy/nursing-excellence/ethics/code-of-ethic s-for-nurses/coe-view-only/

[19] Zickafoose PC. Substance Use Disorder: Efficacy of educational strategies in Delaware. J Contin Educ Nurs. 2018 Jan; 49(1): 42-48. PMid:29384587 https : //doi .org/10.3928/00220124-20180 102-09

[20] American Nurses Association. Addictions and psychological dysfunctions in nursing: The profession's response to the problem. Kansas City (MO): 1984. 2p.

[21] Alunni-Kinkle S. Identifying substance use disorder in nursing. Nurs Manage. 2015 Dec; 46(12): 53-54. PMid:26583341 https: //doi.org/10.1097/01. NUMA .0000473512.38679.ca

[22] Wooten L. Can you recognize substance abuse disorders? ASBN Update. 2018 April/May; 22(2): 14-15. Available from: https://www.healthy.arkansas.gov/images/upload s/pdf/April.May.asbn_ed90_FINAL.pdf

[23] Creswell JW. Research Design: Qualitative, Quantitative, and Mixed Methods Approaches. 4th ed. Los Angeles (CA); 2014. 28p.

[24] Lazarus RS, Folkman S. Stress, Appraisal, and Coping. New York (NY): Springer; 1984.

[25] Macorr Research Solutions. Sample size calculator. 2021. Available from: https://www.macorr.com/sample-size-calcula tor.htm

[26] Hendrix MJ, Sabrittt D, McDaniel A, et al. Perceptions and attitudes toward nursing impairment. Res Nurs Health. 1987 Oct; 10: 323-333. PMid:3671780 https://doi.org/10.1002/nur.4770100506

[27] Smith GB. Attitudes of nurse managers and assistant nurse managers toward chemically impaired colleagues. Image: J Nurs Sch. 1992 Dec; 24(4): 295-300. PMid:1452184 https://doi.org/10.111 $1 / j \cdot 1547-5069.1992 . t b 00736 . x$

[28] Boulton MA, Nosek LJ. How do nursing students perceive substance abusing nurses? Arch Psychiatr Nurs. 2014; 28: 29-34. PMid:24506984 https://doi.org/10.1016/j . apnu. 2013.10 .005

[29] Amankwaa L. Creating protocols for trustworthiness in qualitative research. J Cul Div. 2016 Fall; 23(3): 121-127. 